\title{
The preanesthetic interview by anesthesiology residents: analysis of time and content
}

\author{
Deokkyu Kim, Sung Nyu Lee, Dong-Chan Kim, Jeongwoo Lee, Seonghoon Ko, Sang-Kyi Lee, and \\ Ji-Seon Son
}

Department of Anesthesiology and Pain Medicine, Chonbuk National University Medical School, Jeonju, Korea

Background: A preanesthetic visit can increase a patient's satisfaction. However, it is uncertain whether a preanesthetic visit by an anesthesiology resident can achieve the goal. We studied the time distribution for content of preanesthetic interviews (PI) and evaluated the patient's satisfaction with the PI.

Methods: We recorded the PI duration of 200 patients by a voice recorder. The degrees of patient satisfaction with the PI and the changes of anxiety level after the PI were quantified by a questionnaire. We analyzed the time distribution for content of the PI and the correlation between patient characteristics and PI duration or a patient's satisfaction.

Results: The total PI duration was 184 (134-286) sec (median, 25-75\%), and the time distributions for content of the PI were $8(5-10)$ of greeting, $45(23-70)$ of history taking, $15(10-20)$ of physical examination, 50 (25-98) for obtainingan informed consent, $20(10-30)$ of explanation for anesthetic planning, 15 (5-28) for explanation of patient controlled analgesia, and $10(0-4)$ sec for questions and answers. Age, ASA physical status, and educational level were correlated with PI duration ( $<<0.001$ ). The patient's level of satisfaction was "very satisfied" in $39 \%$, "satisfied" in 50\%, and "moderate" in $11 \%$ of interviews. The anxiety level was "decreased" in 50\%, "increased" in $8 \%$, and "not changed" in $42 \%$ of patients.

Conclusions: Although the duration of a PI given by residents was a relatively short, $89 \%$ of patients of were satisfied with the interview. The PI took a longer time to complete in patients of older age, higher ASA physical status, or lower educational levels. (Korean J Anesthesiol 2012; 62: 220-224)

Key Words: Interview, Patient satisfaction, Visit.

Received: June 13, 2011. Revised: August 3, 2011. Accepted: August 9, 2011.

Corresponding author: Ji-Seon Son, M.D., Department of Anesthesiology and Pain Medicine, Chonbuk National University Medical School, 634-18, Geumam-dong, Deokjin-gu, Jeonju 561-712, Korea. Tel: 82-63-250-1241, Fax: 82-63-250-1240, E-mail: sjs6803@chonbuk.ac.kr (c) This is an open-access article distributed under the terms of the Creative Commons Attribution Non-Commercial License (http:// creativecommons.org/licenses/by-nc/3.0/), which permits unrestricted non-commercial use, distribution, and reproduction in any medium, provided the original work is properly cited. 


\section{Introduction}

A preanesthetic visit is essential for preanesthetic evaluation, anesthetic planning, informed consent, and the anesthesiologistpatient relationship, and contributes to reducing a patient's preoperative anxiety $[1,2]$, which may positively influence anesthetic induction and patient recovery [3-5]. Anxiety also decreases patient satisfaction with the perioperative experience [6].

The doctor-patient relationship is very important to manage patients, and a good relationship has many positive effects on a patient's satisfaction, patient adherence, health outcomes, and the clinicians' sense of well-being [7]. However, it is difficult to achieve a good anesthesiologist-patient relationship, because anesthesiologists have fewer patient contacts than surgeons. Most anesthesiology residents are still inexperienced in their work, received little training regarding doctor-patient communications, and might lack of the skills required to effectively deal with patients. It is uncertain whether the interview during a preanesthetic visit by an anesthesiology resident can achieve the desired goals. We analyzed the time and content preanesthetic interviews (PIs), which were conducted by anesthesiology residents and evaluated the patient's satisfaction withthe PI.

\section{Materials and Methods}

This study was approved by our Institutional Review Board. Two hundred patients who underwent elective surgery were invited on the previous day of surgery to participatein this study. Inclusion criteria were adults aged 18-80 yr and American Society of Anesthesiologists (ASA) physical status I, II, or III. Exclusion criteria included psychiatric disorders or significant speaking and hearing impairment (e.g. dementia, mood disorder, laryngectomy state, deafness, etc.). All anesthesiology residents participating in this study were training in our hospital.

After reviewing a patient's paper or electronic medical records, including past and family history, medication, laboratory tests, image studies, etc., a PI was conducted by 12 anesthesiology residents ( 7 junior and 5 senior residents) and recorded by a voice recorder. After the PI, the times for contents of the interview (greeting, history taking, physical examination, obtainingan informed consent, explanation of anesthetic planning and patient controlled analgesia, and questions and answers) were measured using a voice recorder. The interviews were recorded continuously all at once. To make the measurement of the time for each content easy, the beginnings and the ends of each content had a pause. The time for the content was measured from the first word of the first sentence to the last word of the last sentence in one content. If a sentence was obscure to categorize in a specific content, the sentence was categorized by the context. Total PI duration was calculated as the sum of time for all content. Time measurement for each content by using a voice recorder was done by one anesthesiologist.

To evaluate the degree of a patient's satisfaction with the PI by residents and the change of anxiety level after PI, a questionnaire was provided to the patients after the interview and collected several hours later by another resident who did not interview. The questions regarding a patient's satisfaction were assessed using a 5-point scale (not satisfied at all, not satisfied, moderate, satisfied, or very satisfied), and on a 3-point scale (decrease, no change, or increase) for the change of anxiety level. Also, patient characteristics data were collected from the medical records or the questionnaire.

Data are the median $(25-75 \%)$ or the number of patientsexcept for age and described as mean \pm SD. SigmaStat version 3.5 for Windows (Systat Software Inc., San Jose, CA, USA) was used for data analysis. The strengths of correlation between patient characteristics and PI duration or a patient's satisfaction were assessed by the Pearson product moment test or the Spearman rank order test. Comparisons between males and females were assessed by an unpaired t-test or the MannWhitney rank sum test. $\mathrm{P}<0.05$ was considered statistically significant.

\section{Results}

Patient characteristics are presented in Table 1. The total PI duration was $184(134-286)$ sec (median, 25-75\%), and for the

Table 1. Patient Characteristics

\begin{tabular}{lc}
\hline Sex $(\mathrm{M} / \mathrm{F})$ & $98 / 102$ \\
Age $(\mathrm{yr}$, mean \pm SD) & $45.9 \pm 14.0$ \\
ASA physical status: I/II/III & $137 / 50 / 13$ \\
Education: Primary/middle/high school/university & $32 / 39 / 62 / 67$ \\
Previous anesthesia: Yes/no & $139 / 61$ \\
\hline
\end{tabular}

Values are the number of patients or mean \pm SD.

Table 2. Time Distribution of Interview

\begin{tabular}{lc}
\hline \multicolumn{1}{c}{ Category } & Time $(\mathrm{s})$ \\
\hline Greeting & $8(5-10)$ \\
History taking & $45(23-70)$ \\
Physical examination & $15(10-20)$ \\
Informed consent & $50(25-98)$ \\
Anesthetic plan & $20(10-30)$ \\
Pain control & $15(5-28)$ \\
Question and answer & $10(0-40)$ \\
Total & $184(134-286)$
\end{tabular}

Values are median (range, 25-75\%). 
Table 3. Correlation Coefficients between Patient Characteristics and Interview Duration or Patient Satisfaction

\begin{tabular}{lll}
\hline \multicolumn{1}{c}{ Variables } & Interview duration & \multicolumn{1}{c}{ Satisfaction } \\
\hline Sex $(\mathrm{M} \text { vs. } \mathrm{F})^{*}$ & $\mathrm{P}=0.66$ & $\mathrm{P}=0.65$ \\
Age & $\mathrm{r}=0.35, \mathrm{P}<0.01$ & $\mathrm{r}=-0.01, \mathrm{P}=0.85$ \\
ASA physical status & $\mathrm{r}=0.43, \mathrm{P}<0.01$ & $\mathrm{r}=-0.09, \mathrm{P}=0.19$ \\
Educational level & $\mathrm{r}=-0.18, \mathrm{P}<0.01$ & $\mathrm{r}=0.15, \mathrm{P}=0.06$ \\
Previous anesthesia & $\mathrm{r}=0.08, \mathrm{P}=0.28$ & $\mathrm{r}=0.01, \mathrm{P}=0.92$ \\
\hline
\end{tabular}

Values are correlation coefficient or $\mathrm{P}$ value. *Comparisons between males and females were assessed by unpaired t-test or Mann-Whitney rank sum test.

contents of the PI, the time to obtain an informed consent, and history taking were $45(23-70)$ and $50(25-98)$ sec, respectively (Table 2).

The correlations between patient characteristics and satisfaction or PI duration are presented in Table 3. Age $(r=0.38$, $\mathrm{P}<0.01)$ and ASA physical status $(\mathrm{r}=0.43, \mathrm{P}<0.01)$ had a positive correlation, and educational level $(\mathrm{r}=-0.18, \mathrm{P}<0.01)$ had a negative correlation with PI duration. However, previous anesthetic history had no significant correlation with PI duration. There was no difference in PI duration between males and females.

In the results for each question of the questionnaire, the patient's satisfaction was "very satisfied" in 77 (39\%), "satisfied" in 101 (50\%), "moderate" in 22 (11\%), and "not satisfied" or "not satisfied at all" in none of 200 patients. There was no significant correlation between a patient's satisfaction and PI duration ( $\mathrm{r}$ $=-0.09, \mathrm{P}=0.20$ ) (Fig. 1). The anxiety level was "decreased" in 100 (50\%), "not changed" in 83 (42\%), and "increased" in 17 (8\%) of 200 patients.

\section{Discussion}

This is the first study to analyze preanesthetic interviews, conducted by anesthesiology residents in Korea. The results of our study show that the PI given by residents tooka relatively short time $(\sim 3 \mathrm{~min})$, and that the PI duration was correlated with the age, ASA physical status, and educational level of the patient. Most patients indicated they were satisfied with the PI by residents.

Anesthesiologists preoperatively perform focused clinical examinations, develop a plan of medical intervention and optimization, reduce the patient's anxiety and fears through education, discuss perioperative care and options for postoperative pain control, determine the appropriate laboratory tests and diagnostic studies to perform, discuss anesthesia risks, and obtain informed consent [8]. This interview by an anesthesiologist is generally referred to as a preanesthetic visit or consultation, which is carried out in a face to face meeting

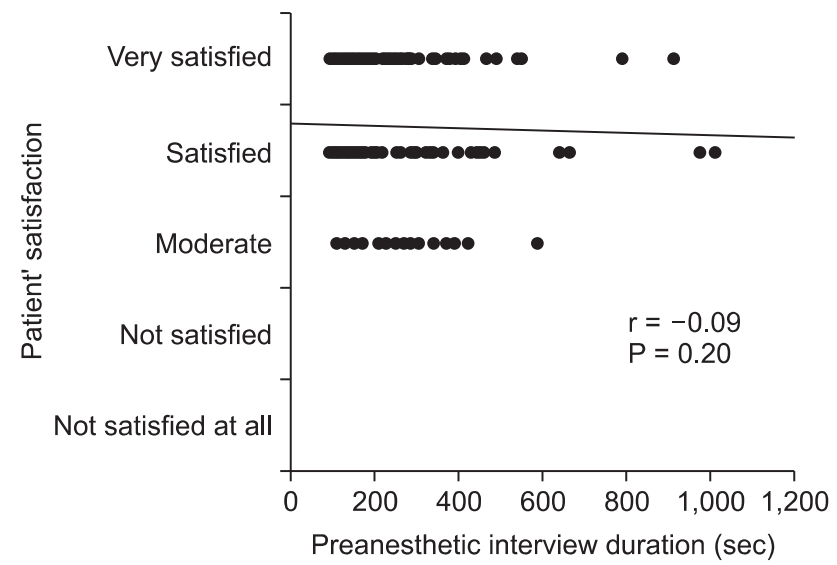

Fig. 1. There was no significant correlation between patientsatisfaction and duration of the preanesthetic interview.

between the anesthesiologist and patient. The advantages ofa preanesthetic visit were previously studied $\sim 50$ years ago, and Egbert et al. [9] reported that a preanesthetic visit by an anesthesiologist is as good as or better than any drug to relieve a preoperative patient's anxiety. Also, an effective preanesthetic visit is increasingly recognized to influence a variety of patient behaviors such as a patient's satisfaction and understanding of medical advice [10].

Sufficient interview time is needed to achieve the advantage of a preanesthetic visit. However, there are few studies for the duration of the preanesthetic visit or interview. Soltner et al. [11] reported that the preanesthetic consultation duration took $\sim 10$ min in patients undergoing a day-care gynecologic procedure. In the other study [12] for the usefulness of video about general information onanesthesia before the interview, the interview duration without video was $<20 \mathrm{~min}$. However, in these 2 studies, it is unknown whether the duration of the interview only counted the conversation between anesthesiologists and patients. The median value of PI duration in our results was 184 $\sec (\sim 3 \mathrm{~min})$, which consistedonly of a face-to-face meeting with patients and did not include the review for a patient's paper or electronic medical records, including past and family history, medication, laboratory tests, and image studies. Furthermore, PI duration was measured by only conversation between anesthesiologists and patients in a recorded PI. Therefore, the real preanesthetic visit may take much longer than in our result.

Our results for the factors influencing interview duration cannot be compared with other studies because they have not been previously studied. In our study, age, ASA physical status, and educational level were correlated with PI duration. We can assume that older patients had a higher grade of ASA physical status, and required a longer duration for obtaining informed consent. Educational level $(r=-0.18)$ had a lesser influence on PI duration because it has a lower correlation 
coefficient compared with age $(\mathrm{r}=0.35)$ and ASA $(\mathrm{r}=0.43)$. Higher educational level can be also presumed to result in less PI duration due to a patient's the better ability to understand, but the tendency that older patients have generally lower educational levels in Korea should be also considered. Regarding time required for content of the PI, the durations needed for obtaining an informed consent and history taking were $>50 \%$ of the PI duration. This shows that anesthesiologists lead the interview, and a certain amount of time was necessary to obtain an informed consent and complete history taking for each patient in our study. Otherwise, in the duration of questions and answers, median value stended towards a minimum value. This means that the number of questions varied for each patient, or no question was asked in a number of patients. We assume that a patient's personal characters such as curiosity and inquisitiveness had an effect on the time for questions and answers.

To achieve the goal of the preanesthetic visit, not only sufficient interview duration is needed but good communication skills as well. In many clinical fields, both technical and non-technical skills are needed to care for patients $[7,13]$. Unfortunately, because anesthesiologists have less contact with patients and their guardians than other clinical fields, the communication skill training has been neglected in anesthesiology residency training. Moreover, most residents lack practice experience, do not have enough time, and received little training in doctor-patient communication skills required to effectively deal with patients. However, Harms et al. [14] reported that training in communication skills reduces a patient's anxiety, improves patient satisfaction, and emphasized the importance of a communication skill training program in anesthesiology residency.

Our study has several limitations. First, a patient's satisfaction and level of anxiety are complex psychological phenomena and should be assessed by multi-item questionnaires that have been shown to be reliable and valid [2]. In our study, the patient's satisfaction for the PI was "very satisfied" in 39\% and "satisfied" in $50 \%$, which was relatively high, but this has to be cautiously interpreted because the data reflect subjective answers by patients. Also, because patients may think that their negative answers result in a disadvantage, the patients were most likely to answer positively. Therefore, the patient's satisfaction with PI by residents was high, but it is difficult to demonstrate the usefulness of a PI by residentsin our study. More studies are necessary to evaluate the effectiveness of preanesthetic interviews by residents.

Second, previous studies have shown that a preanesthetic visit contributes to reducing a patient's preoperative anxiety, but in our study, patients' anxiety after PI by residents were decreased in only $50 \%$ and not changed in $42 \%$ of patients. On the contrary, $8 \%$ of patients had an increase in anxiety. The relatively short duration of the PI and the lack of communication skills of residents resulted in a negative outcome for decreasing patient anxiety. It is thought that a risk-focused interview could increase a patient's anxiety. Also, because we did not evaluate anxiety levels before and after a PI, our results cannot demonstrate that the PI by residents can reduce patient anxiety. However, we believe that a PI by a resident was helpful in decreasing patient preoperative anxiety,compared to when the interview was not performed.

Third, our results did not consider the features of 12 residents. They had different experience regarding interviewing and communication skills, and those differences may have influenced the preanesthetic visit. We think that astudy on patientsatisfaction according to the degree of resident training would be interesting.

Previous studies $[2,12,15,16]$ have shown that good communication skills with video materials are effective to increase the patient's satisfaction during preanesthetic visits. Snyder-Ramos et al. [15] reported that patent satisfaction and understanding were higher when using a documentary video than the interview alone. Also, Salzwedel et al. [12] demonstrated that the use of a risk-focused video is superior to the interview alone on for achieving patient satisfaction and providing knowledge, but the patient's preoperative anxiety was not altered by a risk-focused video. Garden et al. [17] and Lee et al. [2] showed that there was no significant change in anxiety levels after additional written information was provided to patients. However, Kain et al. [16] reported that a multimodal approach including the provision of video material, a preoperative operating room visit, and parent coaching can successfully reduce anxiety in pediatric patients and their parents. When a premedication for anxiety is not used, we believe that the best way to decrease a patient's anxiety is to build a rapport with a patient through good communication during the preanesthetic visit.

In conclusion, the duration of a PI by residents are correlated with age, ASA physical status, and educational level of patients, and informed consent and history taking were the major content of the PI. The patient's satisfaction for the PI by residents was high, but it is difficult to demonstrate the usefulness of an interview by a resident in our study. Further studies regarding patient satisfaction and anxiety improvement resulting from a preanesthetic interview by residents are necessary.

\section{References}

1. Klafta JM, Roizen MF. Current understanding of patients' attitudes toward and preparation for anesthesia: a review. Anesth Analg 1996; 83: 1314-21.

2. Lee A, Chui PT, Gin T. Educating patients about anesthesia: a 
systematic review of randomized controlled trials of media-based interventions. Anesth Analg 2003; 96: 1424-31.

3. Kindler CH, Harms C, Amsler F, Ihde-Scholl T, Scheidegger D. The visual analog scale allows effective measurement of preoperative anxiety and detection of patients' anesthetic concerns. Anesth Analg 2000; 90: 706-12.

4. Goldmann L, Ogg TW, Levey AB. Hypnosis and daycase anaesthesia. A study to reduce pre-operative anxiety and intra-operative anaesthetic requirements. Anaesthesia 1988; 43: 466-9.

5. Scott LE, Clum GA, Peoples JB. Preoperative predictors of postoperative pain. Pain 1983; 15: 283-93.

6. Thomas T, Robinson C, Champion D, McKell M, Pell M. Prediction and assessment of the severity of post-operative pain and of satisfaction with management. Pain 1998; 75: 177-85.

7. Brown JB, Boles M, Mullooly JP, Levinson W. Effect of clinician communication skills training on patient satisfaction. A randomized, controlled trial. Ann Intern Med 1999; 131: 822-9.

8. Fischer SP, Bader AM, Sweitzer B. Preoperative evaluation. In: Miller's anesthesia. 7th ed. Edited by Miller RD, Eriksson LI, Fleisher LA, Wiener-Kronish JP, Young WL: Philadelphia, Churchill Livingstone/Elsevier Inc. 2009, pp 1001-2.

9. Egbert LD, Battit G, Turndorf H, Beecher HK. The value of the preoperative visit by an anesthetist. A study of doctor-patient rapport. JAMA 1963; 185: 553-5.

10. Kindler CH, Szirt L, Sommer D, Hausler R, Langewitz W. A quantitative analysis of anaesthetist-patient communication during the pre-operative visit. Anaesthesia 2005; 60: 53-9.

11. Soltner C, Giquello JA, Monrigal-Martin C, Beydon L. Continuous care and empathic anaesthesiologist attitude in the preoperative period: impact on patient anxiety and satisfaction. Br J Anaesth 2011; 106: 680-6.

12. Salzwedel C, Petersen C, Blanc I, Koch U, Goetz AE, Schuster M. The effect of detailed, video-assisted anesthesia risk education on patient anxiety and the duration of the preanesthetic interview: a randomized controlled trial. Anesth Analg 2008; 106: 202-9.

13. Fletcher GC, McGeorge P, Flin RH, Glavin RJ, Maran NJ. The role of non-technical skills in anaesthesia: a review of current literature. $\mathrm{Br}$ J Anaesth 2002; 88: 418-29.

14. Harms C, Young JR, Amsler F, Zettler C, Scheidegger D, Kindler CH. Improving anaesthetists' communication skills. Anaesthesia 2004; 59: 166-72.

15. Snyder-Ramos SA, Seintsch H, Bottiger BW, Motsch J, Martin E, Bauer M. Patient satisfaction and information gain after the preanesthetic visit: a comparison of face-to-face interview, brochure, and video. Anesth Analg 2005; 100: 1753-8.

16. Kain ZN, Caldwell-Andrews AA, Mayes LC, Weinberg ME, Wang SM, MacLaren JE, et al. Family-centered preparation for surgery improves perioperative outcomes in children: a randomized controlled trial. Anesthesiology 2007; 106: 65-74.

17. Garden AL, Merry AF, Holland RL, Petrie KJ. Anaesthesia information - what patients want to know. Anaesth Intensive Care 1996; 24: 594-8. 